\title{
Depth of anterior chamber after cataract extraction
}

\author{
M. S. NORN \\ From the Department of Ophthalmology, Kommunehospitalet, Copenhagen, Denmark
}

SUMMARY A total of 80 patients with senile cataract had the anterior eye chamber depth measured optically by means of Haag-Streit's attachment II. The distance to the lower pupillary border was $2.59 \pm 0.05 \mathrm{~mm}$ (mean $\pm \mathrm{SEM}$ ) preoperatively. It increased gradually after cataract extraction to $3.33 \pm 0.04 \mathrm{~mm}$, measured 4 months after the operation. The increase of depth was the greatest in patients with a flat chamber and in elderly patients.

The central chamber depth decreased gradually after the operation (from $2 \cdot 82 \pm 0.05 \mathrm{~mm}$ preoperatively to $1.95 \pm 0.13 \mathrm{~mm} 4$ months postoperatively). The number of vitreous prolapse cases rose from 68 to $87.5 \%$ in 4 months.

These altered chamber depths were observed to bear no relation to postoperative corneal oedema (neither of parenchyma nor of epithelium), intraocular pressure, or bleeding into the chamber.

The depth of the anterior eye chamber generally means the distance centrally from the posterior surface of the cornea to the anterior surface of the lens. Cataract extraction leaves a gap which is filled by aqueous humour and vitreous.

Troutman (1963) measured 99 eyes 3 weeks after cataract extraction, from the anterior corneal surface to the pupillary border. The mean distance was $4.01 \mathrm{~mm}$, suggesting an increased chamber depth. The depth was not measured preoperatively, however. Landegger and Roth (1968) measured 58 aphakic eyes with a Zeiss optical micrometer. They measured at intervals the distance from the posterior corneal surface to the lower pupillary border and noticed stabilisation of the individual value 4 to 6 months postoperatively. The mean value for aphakic eyes was $3 \cdot 8 \pm 0.27 \mathrm{~mm}( \pm S D)$, against $2 \cdot 7 \pm 0.4 \mathrm{~mm}$ for 115 non-operated eyes of another series. Ohashi et al. (1969) measured 55 eyes before and 3 weeks after cataract extraction. The chamber depth was $2.775 \mathrm{~mm}$ before the operation and increased to $2.832 \mathrm{~mm}$ after. The chamber tended to be deeper in cases complicated by rupture of the capsule.

Haag-Streit's attachment II to the slit lamp is an exact and simple apparatus for measuring the chamber depth (cf. Weekers and Grieten, 1961; Lowe, 1966; Alsbirk, 1974; Delmarcelle et al., 1976). The object of the present study has been to monitor the chamber depth of cataractous eyes by measuring

Address for reprints: Professor M. S. Norn, MD, Department of Ophthalmology, Kommunehospitalet, DK-1399 Copenhagen K, Denmark it preoperatively and postoperatively, partly to the lower pupillary border and partly to the most prominent part of the vitreous in the pupil. This procedure allowed us to follow the possible development of a vitreous prolapse and change of the site of the iris diaphragm. Further, it served to assess this development in relation to other parameters, for example, complications of operation, corneal thickness, intraocular pressure.

\section{Patients}

The series under review comprised all the patients admitted consecutively to be operated on for senile cataract in June and August 1976, a total of 86. The patients were examined on the day of admission, and on the third to sixth postoperative days. Finally, they were summoned for follow-up examinations 2 and 4 months after operation. One or both followup examinations failed to be carried out in 6 cases owing to general diseases ( 2 patients admitted to other hospitals, 1 suffering from lumbago) or nonappearance for other reasons. The cataract extractions of these patients having run uncomplicated courses, they were excluded from the investigation. The series thereafter comprised 80 eyes of 80 patients. The age distribution is shown in Table 2.

\section{PROCEDURE}

The cataract extraction was performed by cryoextraction with attendant iridotomy and with limbus-based conjunctival flap, 2 preplaced and as a rule 3 postplaced knotted collagen sutures. Alpha- 
chymotrypsin was used for patients aged under 60 . The operations were carried out by the various ophthalmologists attached to the department (permanent staff and residents).

The chamber depth was measured with HaagStreit's attachment II from the posterior corneal surface without correction for corneal radius. Duplicate determinations were performed, the average value being used. The depth was measured centrally, to the anterior lens surface preoperatively and to the most prominent part of the hyaloid membrane in the pupillary region postoperatively (vitreous chamber depth, abbreviated to VCD). The chamber depth was also measured from the posterior corneal surface to the visible posterior edge of the pupil at 6 o'clock (iris chamber depth, abbreviated to ICD).

The ICD was measured with dilated pupil immediately after the operation according to the usual cataract regimen of the department (scopolamine [hyoscine] eye drops, $2 \%$, once daily), untreated preoperatively, and on the last follow-up examination. The corneal thickness was measured with Haag-Streit's attachment I. All examinations were carried out by the author.

Statistical calculations were performed with Student's $t$ test. The following fractions were calculated: $\mathrm{VCD}_{1} / \mathrm{VCD}_{4}$, which means the ratio between the central chamber depth preoperatively (from posterior corneal surface to anterior lens surface) and that on the last follow-up examination (from posterior corneal surface to anterior vitreous body surface). A high value of the ratio indicates extensive vitreous prolapse. $\mathrm{ICD}_{4} / \mathrm{ICD}_{1}$ is the ratio between the iris chamber depth on the last follow-up examination and preoperatively. A high value indicates postoperative deepening of the chamber, i.e., recession of the iris, at least close to the pupil.

\section{Results}

The investigation gave results confirming the view that the central iris chamber depth gradually increases after cataract extraction. At the same time the central vitreous chamber depth was seen to decrease more and more. In other words, the vitreous prolapse increases gradually.

CENTRAL VitReous CHAMBER DEPTH (VCD) The preoperative VCD value was $2.82 \pm 0.05 \mathrm{~mm}$ (Table 1). This is in agreement with that of other, normal, series (Alsbirk, 1974; Ohashi et al., 1969). The vitreous chamber was significantly less deep 3 to 6 days after the operation $(P<0.001)$. In most cases the space of the lens was filled by a forward prolapsing vitreous (Fig. 1).
On follow-up 2 months after the operation an additional significant reduction of the chamber depth was noticed. A further reduction 4 months postoperatively was not significant.

Thus a progressive vitreous prolapse was observed. It was more pronounced after the patient's discharge than during his stay in hospital. The prolapse seemed in the main to have reached its climax and become stabilised 2 months after the operation.
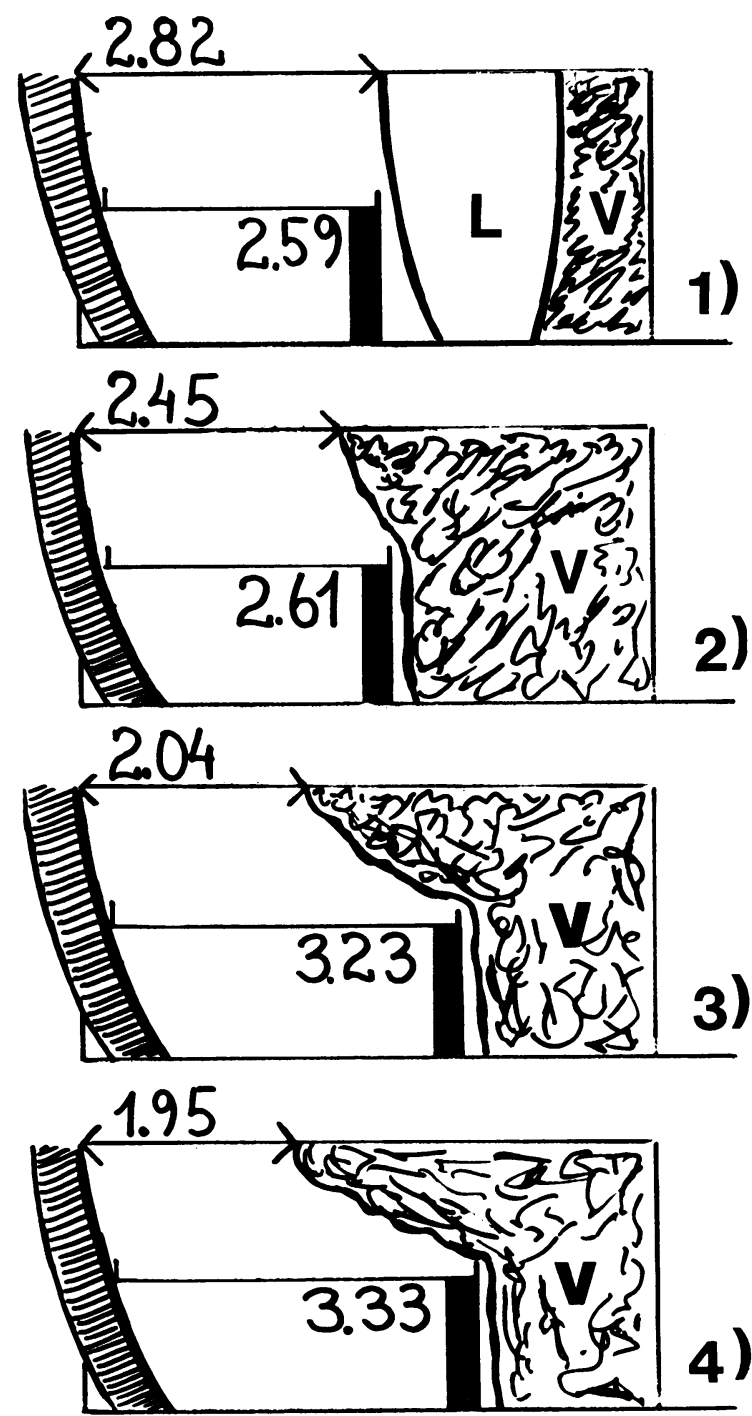

Fig. 1 Chamber depth before and after cataract extraction, average of 80 subjects. The figures indicate vitreous and iris chamber depths respectively.

(1) preoperatively, (2) third to sixth day, (3) 2 months and (4) 4 months after operation. V-vitreous, $\mathrm{L}$-lens 
Table 1 Mean chamber depth before and after cataract extraction (in $\mathrm{mm} \pm S E M$ and coefficient of variation in percent)

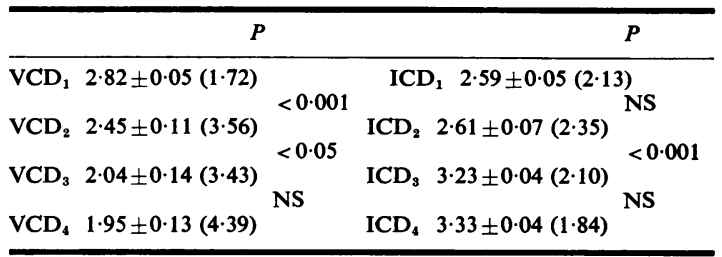

VCD indicates distance from posterior corneal surface to anterior lens surface with respect to HM

ICD is distance from posterior corneal surface to pupil at six o'clock 1: preoperatively, 2: third to sixth postoperative days, 3: 2 months, and 4: 4 months after operation. A total of 80 eyes

This vitreous prolapse might be due to ruptures of the hyaloid membrane (HM). Jaffe (1969) showed that most ruptures of the HM occur 14 to 28 days after operation. In the series under review the postoperative examinations revealed an increasing number of ruptures. The first postoperative examination showed holes in $60 \%$. The chamber was less deep in cases with holes, but the difference was not significant $\left(\mathrm{VCD}_{1} / \mathrm{VCD}_{4} 3.67+0.639\right.$ in 48 with holes, against $2 \cdot 33 \pm 0.530$ in 32 without holes, $t=1 \cdot 61$ ). The ICD showed no difference.

The site of the HM in relation to the iris diaphragm was in $68 \%$ found to be in front of the iris plane on all 3 postoperative examinations (vitreous prolapse). In $20 \%$ the $\mathrm{HM}$ was situated behind the iris plane on the first postoperative examination but in front of the plane on subsequent examinations. In $5 \%$ the HM was behind the iris plane on all examinations, in $6 \%$ in front on the first examination and behind on the last. In 1 case the conditions varied (vitreous prolapse-concaveprolapse again). Thus in most cases vitreous prolapse was noticed, either immediately after operation or developed at a later stage $(87.5 \%)$.

Central vitreo-corneal contact was seen in 1 case only on the first examination. The chamber was reformed before the second examination. Two months postoperatively 8 more such anterior chambers filled with vitreous were found, of which 4 persisted on the last examination, which revealed no fresh cases. The vitreous was thin, frayed, and with holes in all 9 cases. The cornea was-and remained-uninfluenced by the contact.

CENTRAL IRIS CHAMBER DEPTH (ICD)

The ICD was $2.59 \pm 0.05 \mathrm{~mm}$ preoperatively (Landegger and Roth (1968) found $2 \cdot 7 \pm 0.4 \mathrm{~mm}$ ). It was the same immediately after the operation (Table 1) but had increased significantly when measured 2 months later. The additional increase noticed 4 months postoperatively was not significant compared with the value 2 months after operation.

The observations go to show that the part of the iris diaphragm close to the pupil gradually recedes after the operation, and that this recession continues during the first 2 months or so. The deepening possibily includes the whole iris.

This deepening might be thought to be due to oozing of vitreous through the pupil, causing vitreous material from the region behind the iris diaphragm to form a vitreous prolapse in the anterior chamber. However, no simple correlation was found between increasing vitreous prolapse and deepening of the iris chamber.

Table 2 shows that after cataract extraction the depth of the iris chamber increased with rising age (in 57 aged over $70 \mathrm{ICD}_{4} / \mathrm{ICD}_{1}$ was $1.33 \pm 0.032 \mathrm{~mm}$ against only $1 \cdot 21 \pm 0.051$ in 23 younger, $t=2 \cdot 00$, $P<0.05$ ).

Table 3 shows how the iris chamber depth increased the most in the patients with the narrowest chamber preoperatively, i.e., in the patients with the greatest preoperative risk of acute glaucoma attacks.

The diameter of the pupil constitutes a source of error when measuring the ICD (cf. Troutman, 1963). However, in the present investigation $\mathrm{ICD}_{1}$ and $\mathrm{ICD}_{4}$ were measured without using mydriatics.

Table 2 Alteration of chamber depth in relation to age

\begin{tabular}{llll}
\hline Age & $\frac{I C D_{4}}{I C D_{1}}$ & $\frac{V C D_{1}}{V C D_{4}}$ & Number \\
\hline$<50$ & 1.06 & 5.25 & 5 \\
$60-69$ & 1.26 & 2.37 & 18 \\
$70-79$ & 1.34 & 2.90 & 36 \\
$\geqq 80$ & 1.32 & 3.47 & 21 \\
Total & 1.28 & 3.14 & 80 \\
\hline
\end{tabular}

For abbreviations see Table 3

Table 3 Postoperative alteration of chamber depth compared with preoperative depth

\begin{tabular}{|c|c|c|c|c|c|}
\hline \multicolumn{2}{|c|}{$\begin{array}{l}\text { Chamber depth } \\
\text { preoperatively }\end{array}$} & \multirow{2}{*}{$\frac{I C D_{4}}{I C D_{1}} \pm S E M$} & \multirow[t]{2}{*}{$t$} & \multirow[t]{2}{*}{$\boldsymbol{P}$} & \multirow{2}{*}{$\frac{V C D_{1}}{V C D_{4}} \pm S E M$} \\
\hline$(\mathrm{mm})$ & Number & & & & \\
\hline$<2.5$ & 18 & $1 \cdot 60 \pm 0.055$ & \multirow{3}{*}{$\begin{array}{l}5 \cdot 2 \\
4 \cdot 1\end{array}$} & \multirow{3}{*}{$\begin{array}{l}\ll 0.001 \\
\ll 0.001\end{array}$} & $4 \cdot 12 \pm 1 \cdot 649$ \\
\hline$<3.0$ & 29 & $1 \cdot 29 \pm 0 \cdot 024$ & & & $2.92 \pm 0.642$ \\
\hline$\geqq 3 \cdot 0$ & 33 & $1 \cdot 14 \pm 0 \cdot 028$ & & & $2 \cdot 76 \pm 0.603$ \\
\hline
\end{tabular}

$I_{1} D_{4}$ : iris chamber depth 4 months after cataract extraction ICD $_{1}$ : preoperative depth

VCD: central vitreous chamber depth. A total of 80 eyes 


\section{COMPLICATIONS}

Blood in the chamber had no effect on the vitreous chamber depth nor on that of the iris (Table 4). The corneal thickness was on an average $0.494 \mathrm{~mm}$ before the operation and increased after the extraction as in previously reported series (Norn, 1973, 1975). No relationship was found between increased corneal parenchymal thickness or epithelial oedema of the cornea immediately after the operation and alterations of the chamber depth. The intraocular pressure on the third to sixth days bore no relation to alterations in chamber depth. No instances were found in this series of operative vitreous loss, pupil block glaucoma, or extracapsular cataract extraction.

\section{Discussion}

The results of the present investigation bore out the view that the chamber depth, measured from the posterior corneal surface to the lower pupillary border, increases after cataract extraction. The investigation newly disclosed, however, that not only is the chamber depth increased in consequence of removal of the lens, but the deepening continues during the subsequent postoperative months. This late effect may possibly be due to an age-determined shrinking of the vitreous being accelerated by the operation, it being most pronounced in elderly patients. It can only be partially related to the increasing vitreous prolapse, no significant relationship being demonstrable.

Table 4 Complications and their possible relationship to alteration of iris chamber depth (ICD) and vitreous chamber depth (VCD)

\begin{tabular}{llll} 
& $\frac{I C D_{4}}{I C D_{1}}$ & $\frac{V C D_{1}}{V C D_{4}}$ & Number \\
\hline Epithelial oedema & 1.28 & 2.44 & 31 \\
Ruptures of HM & 1.28 & 3.67 & 48 \\
Blood in chamber 1.27 & 2.62 & 27 \\
\hline Total & 1.28 & 3.14 & (88 patients) \\
\hline
\end{tabular}

The increased chamber depth may be in some ways advantageous, provided it includes the peripheral part of the chamber. The fact that the eyes with narrow chamber angles show the most pronounced deepening is a thought-provoking observation. In this connection the peripheral iridotomy may also play a certain role.

The present investigation further disclosed that the vitreous chamber depth alters inversely to the iris chamber depth. Here again it is a question of a gradual development through about 2 postoperative months. Progressive vitreous prolapse is often seen, presumably owing to the pupillary movement having a damaging effect on the vulnerable HM.

Patients discharged with no vitreous prolapse may well develop such prolapse at a subsequent stage of the course. The late vitreous prolapse is presumably harmless, because the vitreous membrane is so thin and damaged.

\section{References}

Alsbirk, P. H. (1974). Optical pachymetry of the anterior chamber. Acta Ophthalmologica, 52, 747-758.

Delmarcelle, Y., François, J., Gos, F., Collignon-Brach, J., Luyckx-Bacus, J., and Verbraeken, H. (1976). Biometrie Oculair Clinique (Oculometrie), pp. 496-497. Masson:Paris.

Jaffe, N. (1969). The Vitreous in Clinical Ophthalmology. C. V. Mosby: St. Louis.

Landegger, G. P., and Roth, N. (1968). Anterior chamber depth and its stability in aphakia. American Journal of Ophthalmology, 65, 706-708.

Lowe, R. F. (1966). New instruments for measuring anterior chamber depth and corneal thickness. American Journal of Ophthalmology, 62, 7-11.

Norn, M. S. (1973). Pachymetric study on the influence of corneal endothelial vital staining. Acta Ophthalmologica, 51, 679-686.

Norn, M. S. (1975). Corneal thickness after cataract extraction with air in anterior chamber. Acta Ophthalmologica, 53, 747-750.

Ohashi, T., Ando, S., and Hoshi, E. (1969). Depth of the anterior chamber in aphakic eyes. Japanese Journal of Clinical Ophthalmology, 23, 730-736.

Troutman, R. C. (1963). Anterior chamber depth in aphakia. Transactions of the American Ophthalmological Society, 61, 385-396.

Weekers, R., and Grieten, J. (1961). Measurement of the depth of the anterior chamber in the clinic. Bulletin de la Société Belge d'Ophtalmologie, 129, 361-381. 